Vol. 30, julho 2014, http://dx.doi.org/10.5380/dma.v30i0.34196

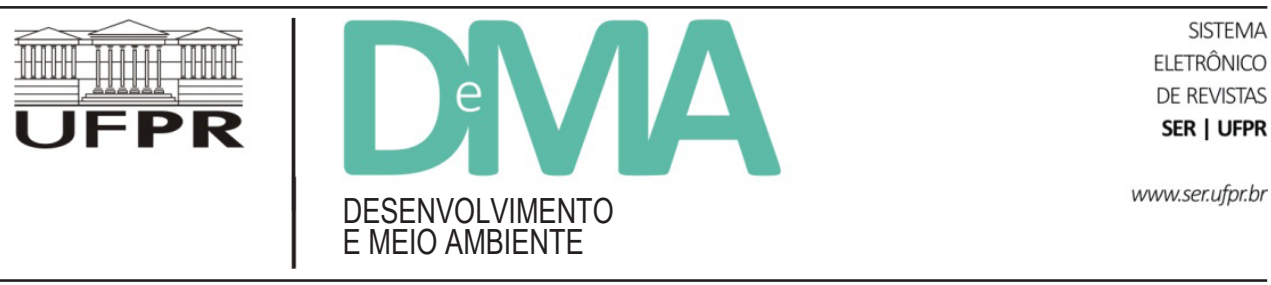

\title{
O uso do conhecimento ecológico tradicional de pescadores no diagnóstico dos recursos pesqueiros em áreas de implantação de grandes empreendimentos
}

\section{The Use of Traditional Ecological Knowledge of Fishers in the Diagnosis of Fishery Resources in Areas of Deployment of Large Projects}

Carolina Rodrigues da Costa DORIA ${ }^{1}$, Maria Alice Leite LIMA², Ariel Rodrigues dos SANTOS ${ }^{3}$, Suelen Taciane Brasil de SOUZA ${ }^{4}$, Maria Olívia de Albuquerque Ribeiro SIMÃO ${ }^{5}$, Adriana Rosa CARVALHO ${ }^{6}$

${ }^{1}$ Doutora em Desenvolvimento Sustentável do Trópico Úmido (UFPA). Professora do Departamento de Biologia da Universidade Federal de Rondônia (UNIR). E-mail: carolinarcdoria@unir.br

${ }^{2}$ Mestra em Ciências Pesqueiras nos Trópicos (UFAM). Pesquisadora colaboradora do Laboratório de Ictiologia e Pesca da Universidade Federal de Rondônia (UNIR). E-mail: alicelima2003@yahoo.com.br

${ }^{3}$ Biólogo (UNIR). Pesquisador colaborador do Laboratório de Ictiologia na Universidade Federal de Rondônia (UNIR). E-mail: ariel_o_santos@hotmail.com

${ }^{4}$ Bióloga (UNIR). Instituto de Estudos e Pesquisas Agroambientais Organizações Sustentáveis. E-mail: suelenbrasil.pesca@gmail.com

${ }_{5}^{5}$ Doutora em Biologia de Água e Pesca Interior (INPA). Professora do Departamento de Biologia da Universidade Federal do Amazonas (UFAM). E-mail: mariaoliviar@uol.com.br

${ }^{6}$ Doutora em Ecologia de Ambientes Aquáticos Continentais (UEM). Professora do Departamento de Botânica, Ecologia e Zoologia da Universidade Federal do Rio Grande do Norte (UFRN). E-mail: acarvalho.ufrn@gmail.com

Artigo: Recebido em: 3 de novembro de 2013; Versão final aceita em: 4 de junho de 2014.

RESUMO A determinação e o monitoramento de impactos de grandes empreendimentos na Amazônia são limitados pela ausência de dados ambientais pretéritos. O presente estudo avalia o uso do Conhecimento Ecológico Tradicional (CET) dos pescadores do médio rio Madeira sobre as espécies comerciais, na geração do conhecimento para monitoramento de grandes empreendimentos hidrelétricos na Amazônia. Foram realizadas reuniões com grupos de pescadores (5 a 10), em sete pontos do Programa de monitoramento pesqueiro da Santo Antônio Energia (SAE), entre abril e dezembro/2009. As reuniões seguiram roteiro semiestruturado a fim de registrar o CET sobre sete variáveis biológicas e a metodologia de mapas mentais para construção de cenários sobre a pesca atual e futura frente à implantação de dois grandes empreendimentos na bacia do Rio Madeira. Os resultados obtidos mostraram que as comunidades apresentaram um conhecimento amplo sobre as principais espécies exploradas na região pela pesca comercial, sendo estes resultados confirmados, em grande parte dos casos (cerca de 70\%),pela informação científica. Este estudo confirma o refinado conhecimento do pescador sobre a biologia das espécies que ele explora e sugere que o CET pode ser utilizado para obtenção de dados biológicos e para 
a construção de cenários para a atividade pesqueira, bases para o manejo adaptativo na fase de monitoramento dos empreendimentos, bem como para o planejamento de políticas de gestão pesqueira na região.

Palavras-chave: etnoictiologia; pesca artesanal; Rio Madeira.

ABSTRACT The determination and monitoring of impacts of large projects in the Amazon are limited by the lack of primary environmental data. We evaluated the use of traditional ecological knowledge (TEK) of fishermen in the middle portion of the Madeira River on the commercial species in the generation of knowledge for monitoring of large hydroelectric dams in the Amazon. Meetings were held with groups of fishermen in 7 points of the fisheries monitoring program of Santo Antônio Energia (SAE), during the period from April to December 2009. Half-structuralized interviews had been carried through in order to register the TEK on 8 biological variables and to construct mental maps that describe scenarios on the fishing front of current and future deployment of two major developments in the Madeira River basin. Overall, the results showed that communities had a wide knowledge about the main species exploited by commercial fishing in the region, and these results were confirmed in most cases (about 70\%) by literature. This study confirms the refined knowledge of the fishermen on the biology of the species they explore and suggests that the TEK should be taken into obtain biological data and the construction of scenarios for the fishery, as well as in the management, conservation actions, and sustainable use of the local fishing resources in the region.

Keywords: ethnoichthyology; artisanal fishing; Madeira River.

\section{Introdução}

Alterações ambientais exercidas pelo ser humano quase sempre afetam negativamente a biodiversidade, pois, em geral, trazem como consequência o declínio de riqueza e diversidade de espécies. Em sistemas lóticos, parte importante destes impactos tem sido decorrente principalmente de modificações provocadas por barramentos de rios para fins de geração de energia elétrica (Richter et al., 1997).

$\mathrm{O}$ barramento de rios resulta, de maneira geral, em modificações nas condições físico-químicas do ambiente, promovendo uma descontinuidade no canal dos rios, alterando a riqueza, composição, distribuição e abundância das espécies (Lowe-McConnell, 1984; Kubecka, 1993; Agostinho et al., 1997; Rodriguez Ruiz, 1998; Agostinho et al., 1999; Bonner \& Wild, 2000; Pettesse \& Petrere, 2012). Estas alterações podem atingir ainda os âmbitos social e econômico da região afetada, em função da modificação no rendimento pesqueiro e/ou causando a substituição de espécies atualmente explotadas pela pesca, tanto em escala local quanto regional (Giusti, 2005). Em regiões amazônicas, onde o peixe é tradicionalmente o principal alimento das comunidades ribeirinhas (Diegues, 1996) e um produto comercial importante para aquisição de renda, o impacto socioeconômico pode ser ainda maior.

Neste contexto, o conhecimento técnico-científico da biodiversidade, o reconhecimento e a compreensão de padrões que estruturam comunidades, a biologia das espécies e a interface que essa diversidade tem com a sociedade no uso destes recursos apresentam um papel relevante (Agostinho \& Gomes, 2005; Doria et al., 2012a). Informações históricas sobre o uso da área, especialmente no que diz respeito à pesca, permitem que se separe os efeitos causados pela construção de barramentos daqueles exercidos por outras atividades (tais como desmatamento, garimpo, sobre-explotação) e fornecem subsídio a tomadas de decisões inerentes a este tipo de empreendimento, tais como a gestão adaptativa, importantes na fase de monitoramento (Ferraz, 2012). Na gestão adaptativa, o aprendizado condiciona o processo que associa o experiente (conhecimento empírico) ao experimental para subsidiar as decisões e se autoavaliar e corrigir a cada resultado proveniente da ação de manejo adotada (Holling, 1973). Os princípios básicos são que não se tem toda a informação para o manejo (pois o conhecimento científico é incompleto), que interações com o ecossistema sempre se desenvolverão e que novas informações sociais, econômicas e biológicas advindas 
das amostragens consecutivas determinarão os novos passos (Meffe et al., 2002).

Discussões atuais sobre regulamentação de amostragens biológicas em estudos de licenciamento ambiental para grandes empreendimentos destacam a necessidade de produção de conhecimento que subsidie decisões racionais dentro do processo de licenciamento. Este conhecimento se baseia principalmente em questões-chave do porquê, do que e de como amostrar. Nesse sentido, diretrizes amostrais têm sido sugeridas, determinando que a área amostral deve idealmente: $i$. representar a área sob a influência do projeto de construção; ii. ser compatível com a biologia do alvo de amostragem; iii. ocorrer tanto em áreas previsivelmente afetadas quanto em áreas de controle, com locais devidamente justificados. Em escala temporal, espera-se que se garanta que a amostragem comece antes do início dos impactos previstos e sua duração no tempo deve ser compatível com o ciclo de vida do alvo de amostragem (Ferraz, 2012).

Em áreas geograficamente isoladas, como na Amazônia, a execução desses estudos se constitui em um enorme desafio, frente ao custo elevado, a ausência de dados pretéritos e as dificuldades logísticas inerentes à região. Isso pode refletir em consideráveis lacunas de conhecimento, limitar a elaboração de indicadores que possam ser empregados de modo factível no monitoramento e na quantificação dos possíveis impactos do empreendimento e no sucesso de estratégias de mitigação de impactos propostas, a exemplo da construção de escadas e/ou canais de transposição (Britski, 1994; Agostinho \& Gomes, 2005).

Nas últimas décadas, vários pesquisadores têm proposto o uso do Conhecimento Ecológico Tradicional (CET) como ferramenta importante na busca de informações bioecológicas sobre os recursos pesqueiros, baseando-se na estreita relação de uso e dependência de recursos naturais exercida por comunidades humanas que praticam atividades tradicionais (Johannes, 1989; Begossi, 2012). Para Sarda e Maynou (1998), essa sabedoria específica local pode apontar para novos campos de estudo de ecossistema, com a participação direta das comunidades tradicionais nos programas de gestão, conduzindo, dessa forma, a novos insights científicos. A combinação do conhecimento científico com o chamado conhecimento tradicional dos pescadores tem sido amplamente utilizada para tornar mais estreito o diálogo entre usuários do recurso e gestores, permitindo o surgimento de políticas com melhores chances de sustentabilidade (Azevedo \& Apel, 2004; Berkers et al., 2006; Begossi, 2012). Em algumas regiões ainda pouco estudadas, como a Amazônia e outros países tropicais em desenvolvimento, estes estudos podem ser a única fonte de informações relativas às condições passadas sofridas pelo ecossistema $\mathrm{e}$ recursos pesqueiros explorados (Johannes, 1998; Ruddle, 2000; Silvano \& Valbo-Jorgensen, 2008).

No Brasil, a importância do uso do Conhecimento Ecológico Tradicional como ferramenta para o manejo pesqueiro tem sido aos poucos reconhecida, analisada e aplicada por uma variedade de pesquisadores nos diversos ambientes e enfoques: comportamento reprodutivo, ecologia trófica, migração, crescimento, mortalidade, efeitos antrópicos, recrutamento pesqueiro, entre outros (Carvalho, 2002; Costa-Neto et al., 2002; Batistella et al., 2005; Gerhardinger et al., 2006; Barboza \& Pezzuti, 2011; Galvão de Lima \& Batista, 2012).

Com base nestas considerações, o CET dos pescadores do médio rio Madeira foi utilizado no Programa Básico Ambiental da Santo Antônio Energia, empresa responsável pela implantação da Usina Hidrelétrica de Santo Antônio, no rio Madeira, como registro complementar ao conhecimento técnico-científico sobre a ecologia e biologia das espécies de peixes importantes na pesca comercial local. O presente estudo apresenta a proposta metodológica utilizada e avalia o uso do CET na geração do conhecimento para monitoramento de grandes empreendimentos hidrelétricos na Amazônia. Para tanto, teve como perguntas centrais: 1) qual o CET sobre a ecologia e biologia das principais espécies exploradas pela pesca de caráter comercial por pescadores da porção média do rio Madeira?; 2) quais as informações oferecidas pelo CET que são comuns ao conhecimento científico?; 3) qual a percepção dos pescadores sobre os cenários atual e futuro da atividade pesqueira frente à implantação do empreendimento hidrelétrico? 


\section{A pesca na porção média do rio Madeira}

O rio Madeira tem uma área de drenagem cobrindo cerca de $1.380 .000 \mathrm{~km}^{2}$ de extensão e é um dos mais importantes tributários da bacia Amazônica (Goulding et al., 2003). A pesca na região tem caráter artesanal de pequena escala e apresenta importância socioeconômica para as comunidades ribeirinhas da região. A produção pesqueira, desembarcada em sua grande maioria no mercado de Porto Velho, resulta principalmente de pescarias realizadas à jusante das cachoeiras do rio Madeira e tem média anual entre 700 t e 1.000 t (Doria et al., 2012a).

O fragmento da bacia do rio Madeira abordado no presente estudo, até o final do período de aplicação da metodologia, consistiu em um trecho original, livre de barramentos, que a partir do ano de 2012 foi interrompido pelos aproveitamentos hidrelétricos - AHE - Jirau à montante da comunidade de Jacy-Paraná e AHE Santo Antônio, situado a $10 \mathrm{~km}$ do município de Porto Velho.

A área de estudo compreendeu parte do médio rio Madeira, com os pontos amostrais estabelecidos nas principais localidades de pesca comercial e desembarque pesqueiro na porção à montante da UHE Santo Antônio: Cachoeira do Teotônio e Jacy-Paraná; na porção à jusante: São Sebastião, Engenho Velho, São Carlos, Calama e Humaitá (Figura 1).

\section{Metodologia}

\subsection{Levantamento etnoictiológico}

Sete variáveis descritoras de migração, alimentação e reprodução foram selecionadas para constituir a base de dados para o monitoramento dos recursos pesqueiros e da atividade pesqueira após a implantação do barramento. Foram elas:

- Migração: 1. Presença de comportamento migratório; 2. Motivo da migração (reprodutiva ou trófica); e 3. Área de migração da espécie;

- Alimentação: 4. Tipo de alimento consumido pela espécie;
- Reprodução: 5. Período de reprodução; 6. período de maior grau de gordura cavitária; e 7. tamanho de maturação.

Os dados foram coletados por entrevistas por meio de questionários semiestruturados aplicados aos pescadores de cada comunidade durante seis excursões realizadas entre outubro e dezembro de 2009. Foram feitas questões sobre percepções ecológicas e biológicas desses pescadores que permitissem avaliar os aspectos cognitivos das variáveis biológicas e ecológicas selecionadas.

Em cada comunidade foi entrevistado um conjunto de 6 a 7 pescadores-chave; entretanto, esse número variou de acordo com a disponibilidade dos pescadores experientes. A identificação desses pescadores ocorreu por meio de visitas técnicas prévias, ocasião em que eles foram contatados, totalizando, ao longo do trecho estudado, 62 pescadores.

A escolha das categorias de pescado analisadas foi baseada na captura registrada por meio do Subprograma de Monitoramento da Atividade Pesqueira do AHE Santo Antônio, que coletou dados de desembarque pesqueiro dos pescadores ativos nas sete comunidades estudadas. Portanto, o número de espécies ou categorias avaliadas variou de acordo com a produção total $(\mathrm{kg})$ entre as comunidades (Tabela 1).

A consistência do conhecimento dos pescadores foi observada mediante a construção de tabelas de cognição comparada, em que os resultados etnológicos obtidos são confrontados com a literatura e os dados de biologia e ecologia coletados experimentalmente para o mesmo trecho. Para a análise comparativa dos dados, foi realizada uma análise percentual, que consiste no número total de comunidades questionadas para determinada etnoespécie, considerando, assim, informações fornecidas pelos pescadores que apresentaram a consonância igual ou maior que $50 \%$ determinada pela frequência de ocorrência das respostas entre as comunidades.

Na comparação da informação sobre o tamanho da primeira maturação, foram considerados valores semelhantes de até $30 \mathrm{~mm}$ para peixes de pequeno porte, de até $50 \mathrm{~mm}$ para peixes de médio porte e até $100 \mathrm{~mm}$ para peixes de grande porte. 


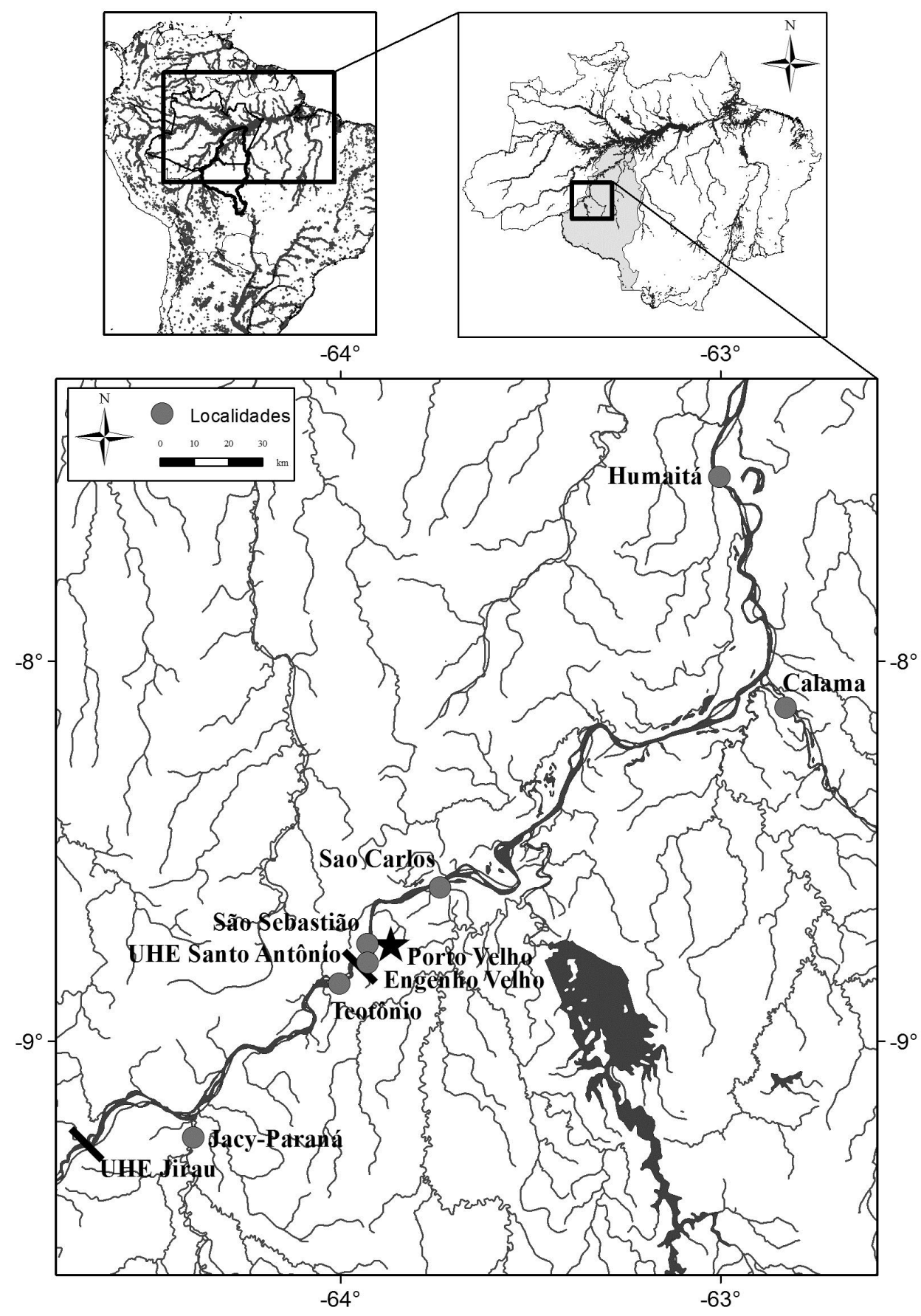

FIGURA 1 - Localização geográfica da área de estudo. 
TABELA 1 - Lista de categorias de pescado avaliadas, respectivos nomes científicos e comunidades onde foram registradas informações sobre a categoria de pescado. Legenda: 1 - Jacy-Paraná; 2 - Cachoeira do Teotônio; 3 - São Sebastião; 4 - Engenho Velho; 5 - São Carlos; 6 - Calama; 7 - Humaitá.

\begin{tabular}{|c|c|c|}
\hline Categoria do pescado & Nome científico & Localidade \\
\hline Acará açú & Astronotus crassipinnis & 7 \\
\hline Apapá amarelo & Pellona castelnaeana & 3,4 \\
\hline Aracu cabeça gorda & Leporinus spp. & 7 \\
\hline Aracu comum & Schizodon fasciatus & 7 \\
\hline Babão & Brachyplatystoma platynemum & 3,4 \\
\hline Barba-chata & Pinirampus pirinampu & $2,3,4,5$ \\
\hline Caparari & Pseudoplatystoma tigrinum & 2 \\
\hline Curimatã & Prochilodus nigricans & $1,4,5,6,7$ \\
\hline Dourada & Brachyplatystoma rousseauxii & $2,3,4,6,7$ \\
\hline Filhote & Brachyplatystoma filamentosum & $1,2,3,4,5,6$ \\
\hline Jaraqui escama fina & Semaprochilodus taeniurus & $1,5,6$ \\
\hline Jaraqui escama grossa & Semaprochilodus insignis & $1,6,7$ \\
\hline Jatuarana & Brycon amazonicus & $1,2,5,6,7$ \\
\hline Jaú & Zungaro zungaro & $1,2,3,4$ \\
\hline Mapará & Hypophthalmus spp. & 3,4 \\
\hline Matrinxã & Brycon melanopterus & 6 \\
\hline Pacu comum & Mylossoma duriventre & $1,5,6,7$ \\
\hline Pescada & Plagioscion squamosissimus & 1 \\
\hline Piramutaba & Brachyplatystoma vaillantii & $2,3,4$ \\
\hline Pirapitinga & Piaractus brachypomus & 1 \\
\hline Pirarara & Phractocephalus hemioliopterus & $2,4,6$ \\
\hline Sardinha comprida & Triportheus auritus & $5,6,7$ \\
\hline Surubim lenha & Sorubimichthys planiceps & 2 \\
\hline Surubim/Pintado & Pseudoplatystoma spp. & $1,2,3,4,5,7$ \\
\hline Tamoatá & Hoplosternum littorale & 7 \\
\hline Traíra & Hoplias malabaricus & 1 \\
\hline Tucunaré & Cichla pleiozona & 1 \\
\hline
\end{tabular}

\subsection{Construção de cenários}

Informações sobre o ordenamento da atividade pesqueira, conflitos, cenários atual e futuro (após a implantação dos barramentos) foram registradas por localidade, por meio da construção dos mapas mentais, de acordo com a metodologia proposta por Kozel (2001). Esta metodologia, qualitativa e participativa, propicia o envolvimento dos pescadores locais na construção do conhecimento, na discussão de cenários e na proposição de estratégias importantes para a conservação das espécies e manutenção da atividade pesqueira local. 
Os mapas mentais construídos com os pescadores foram digitalizados (Figura 2) e redesenhados a fim de subsidiar a construção de cenários no formato de mapas pictográficos, recorrendo ao uso de signos figurativos simplificados que representam coisas e objetos do meio envolvente (pictogramas), facilitando a visualização das situações apresentadas pelos pescadores (cenários atuais) ou hipotetizadas por eles (cenários futuros) a partir da implantação do empreendimento.

Para análise dos conflitos da pesca, foram utilizados também registros oriundos das reuniões para levantamento do CET e observações registradas nos diários de campo da equipe técnica.

\subsection{Coleta experimental de dados biológicos e ecológicos}

As informações biológicas utilizadas neste trabalho para comparar com o CET foram obtidas durante o Programa de Ecologia e Biologia da Santo Antônio Energia, em parceria com o Laboratório de Ictiologia e Pesca da Universidade Federal de Rondônia. As pescarias experimentais foram bimensais e ocorreram de abril de 2009 a janeiro de 2012, em 14 pontos de coleta ao longo do médio rio Madeira.

Foram utilizadas redes de espera de diferentes tamanhos e malhas (30 a $200 \mathrm{~mm}$ entre nós opostos) e

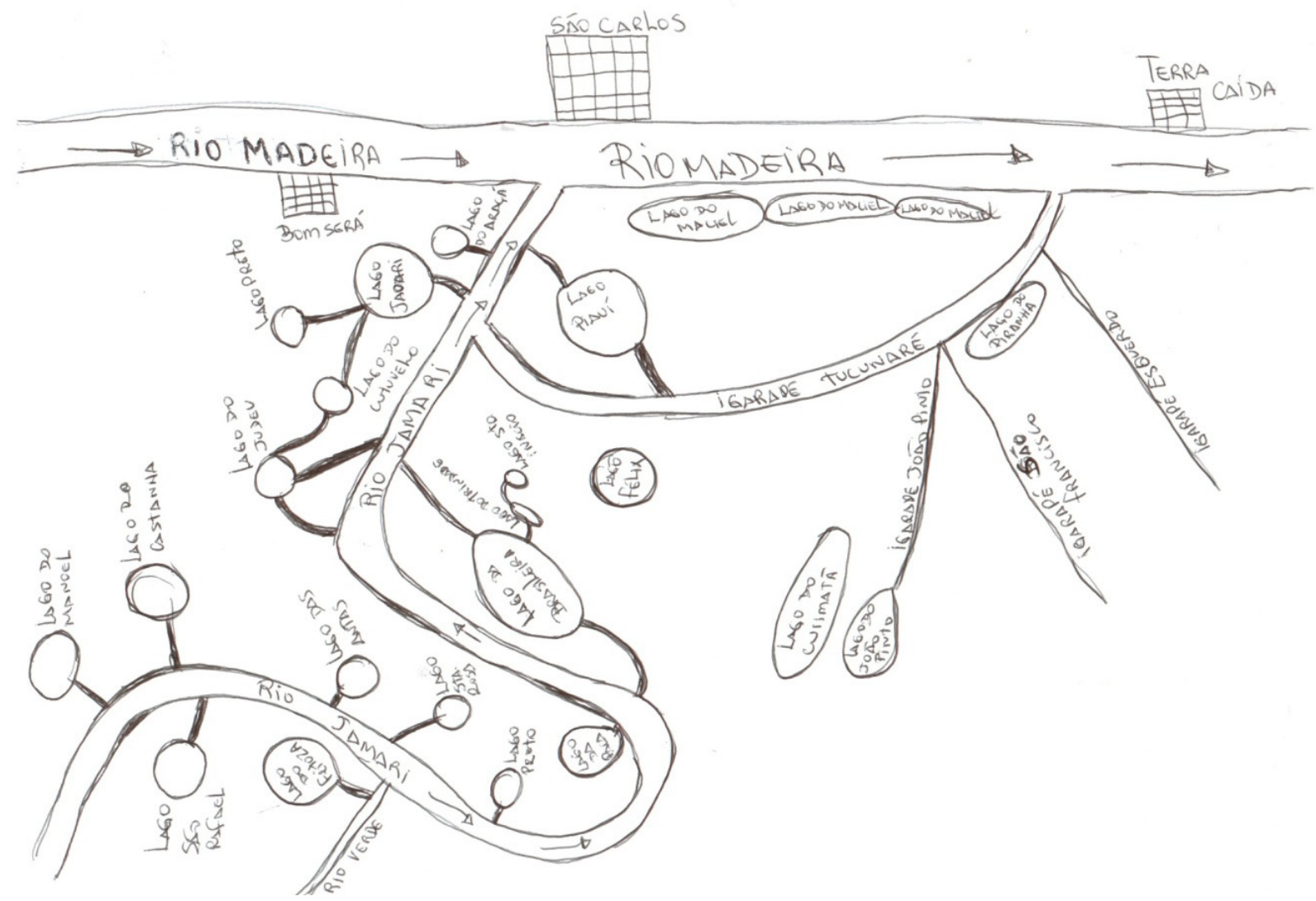

FIGURA 2 - Imagem digitalizada do mapa mental da pesca produzido pelos pescadores da localidade de São Carlos. 
groseira com esforço de 15 anzóis, ambos instrumentos armados durante o período de 24 horas e revisados a cada quatro horas. Para cada exemplar capturado foram registrados o comprimento padrão - $\mathrm{Cp}$ (em milímetros), peso total - Pt (em gramas) e foram determinados macroscopicamente sexo e estádios de maturação gonadal segundo a escala definida por Vazzoler (1996). Adicionalmente, foram avaliados o grau de gordura cavitária - GG (Santos, 1991) e a composição da dieta.

\subsection{O conhecimento ecológico tradicional como fonte de informações biológicas}

O conhecimento ecológico tradicional (CET) é definido na literatura como o conhecimento acumulado sobre espécies, ambiente e as interações entre eles e que é repassado de geração para geração (Drew, 2005). Diversos autores reconhecem a importância desse conhecimento e a sua incorporação às informações técnico-científicas disponíveis para subsidiar políticas públicas de conservação e o manejo pesqueiro regional (Diegues et al., 2000; Costa-Neto et al., 2002; Silvano \& Begossi, 2002; Batista et al., 2004; Drew, 2005; Berkers et al., 2006).

As comunidades amazônicas são reconhecidas pelo apurado conhecimento tradicional acumulado durante várias gerações sobre a região ou ambiente em que vivem e sobre as espécies de animais e vegetais que exploram. Esse conhecimento é construído em resposta à necessidade de sobreviver da floresta e dela retirar os produtos que geram sua reprodução social. Nas pescarias, o convívio diário do ribeirinho com o ambiente aquático, somado à necessidade de exploração, lapidou a experiência do pescador, que é capaz de reconhecer com eficiência a distribuição das espécies exploradas, as variações sazonais na abundância e os movimentos migratórios (Doria et al., 2008).

A pesca no rio Madeira no trecho estudado é realizada por pescadores artesanais, polivalentes e oportunistas que exploram uma série de espécies em diferentes épocas do ano de acordo com a disponibilidade sazonal (Doria et al., 2012b). Essa atividade está presente em populações ribeirinhas, indígenas e em uma parcela da população de centros urbanos das cidades localizadas neste trecho e está relacionada principalmente com a subsistência (consumo) e a geração de renda (venda).

Os pescadores da região têm demonstrado um refinado conhecimento dos ecossistemas em relação às espécies de peixes com peculiaridades sobre territorialidade, espectro alimentar, áreas de alimentação e atividade reprodutiva (Morril, 1967; Ankei, 1982; Begossi \& Garavello, 1990; Begossi \& Figueiredo, 1995; Silvano \& Begossi, 2002; Batistella et al., 2005; Doria et al., 2008).

Os resultados obtidos no presente estudo confirmaram essa hipótese. Os pescadores detêm informações sobre a alimentação, reprodução e migração das espécies que utilizam como alvo para pesca comercial. Dentre as variáveis avaliadas, observamos que a porcentagem de confirmação do CET com os resultados experimentais esteve entre $70 \%$ e $73 \%$, exceto para o período reprodutivo, que foi de $55 \%$. Este resultado reflete a observação que o pescador faz do peixe no ambiente e se transmite oralmente a partir da prática da pesca com pescadores mais experientes.

A pesca nestas localidades está relacionada principalmente aos movimentos migratórios reprodutivos e tróficos. Os pescadores conhecem a rota de migração, mas este conhecimento é limitado ao período em que o peixe ocorre ou é capturado em sua comunidade (Tabela 2). Dentre as 20 categorias investigadas e que tiveram sua rota informada pelos pescadores, 14 (70\%) foram confirmadas na literatura. $\mathrm{O}$ motivo desencadeador da migração foi apresentado somente para $35 \%$ das categorias avaliadas.

Os itens alimentares utilizados pelas espécies são amplamente reconhecidos pelos pescadores, em especial devido à importância desta informação para determinação do tipo de isca a ser usada em certos apetrechos de pesca. Para o monitoramento, essa informação auxilia na determinação da categoria trófica e na elaboração de inter-relações tróficas que ocorrem no ambiente (Figura 3).

De acordo com o relato dos pescadores, podemos classificar babão, barba-chata, dourada, filhote, piraíba, piramutaba e traíra como piscívoros (se alimentam de outros peixes). O jaraqui-escama-grossa, segundo a definição dada pelos pescadores, é um detritívoro (pois se alimenta de lodo e detritos). As espécies de pacu, pirapitinga, pirarara, sardinha e o surubim seriam 
TABELA 2 - Conhecimento Ecológico Tradicional (CET) sobre migração das espécies-alvo das pescarias nas localidades do trecho de estudo. Legenda: $\mathrm{SC}=$ Sobem o rio Madeira atravessando a Cachoeira do Teotônio; NSC = Não sobem a Cachoeira do Teotônio; NS = Não sabem informar; X: informação confirmada na literatura (Torrente-Vilara, 2009); •: informação não confirmada na literatura (Torrente-Vilara, 2009).

\begin{tabular}{|c|c|c|c|}
\hline \multirow{2}{*}{ Espécie } & \multicolumn{2}{|c|}{ Rota migratória } & \multirow{2}{*}{ Razão ecológica } \\
\hline & SC & NSC & \\
\hline Piau comum & & $\bullet$ & NS \\
\hline Piau cabeça gorda & & $\bullet$ & Reprodução \\
\hline Barba-chata & & $\mathbf{X}$ & NS \\
\hline Caparari & & $\bullet$ & NS \\
\hline Curimatã & $\mathbf{X}$ & & Reprodução e alimentação \\
\hline Dourada & $\mathbf{X}$ & & Alimentação \\
\hline Filhote/Piraíba & $\mathbf{X}$ & & Alimentação \\
\hline Jaraqui-escama-fina & & $\bullet$ & NS \\
\hline Jaraqui-escama-grossa & & $\bullet$ & NS \\
\hline Jatuarana & $\mathbf{X}$ & & Reprodução e alimentação \\
\hline Jaú & $\mathbf{X}$ & & NS \\
\hline Pacu & $\mathbf{X}$ & & Reprodução \\
\hline Piramutaba & & $\mathbf{X}$ & NS \\
\hline Pirapintinga & $\mathbf{X}$ & & Reprodução \\
\hline Pirarara & & $\bullet$ & NS \\
\hline Pirarucu & & $\bullet$ & NS \\
\hline Sardinha & $\mathbf{X}$ & & NS \\
\hline Surubim & $\mathbf{X}$ & & NS \\
\hline Surubim lenha & $\mathbf{X}$ & & NS \\
\hline Tucunaré & & $\mathbf{X}$ & NS \\
\hline
\end{tabular}

omnívoros (pois se alimentam tanto de material vegetal como animal). Estas categorias tróficas de fato foram confirmadas pelas informações de dieta obtidas das pescarias experimentais.

As informações referentes à reprodução das espécies, tais como o período reprodutivo e de desova, grau de gordura cavitária e tamanho de primeira maturação, têm uma estreita relação com o ciclo de vida da espécie e são importantes para definições de padrões reprodutivos antes da implantação do barramento. Alterações nesses valores podem suscitar inferências sobre mudanças na reprodução provocadas pela alteração ambiental e que potencialmente poderiam interferir negativamente no recrutamento das espécies.

O grau de gordura acumulado na cavidade abdominal está relacionado à reserva energética anterior ao período de desova (Vazoller, 1996). Segundo os pescadores, o período de vazante e seca é o período em que a maioria dos peixes está com maior quantidade de gordura armazenada na cavidade abdominal (Tabela 3). Segundo eles, isso provavelmente se deve à maior abundância de alimento nas áreas de igapós e lagos no período antecedente (a cheia) que permite o armazenamento de gordura (período gordo). 

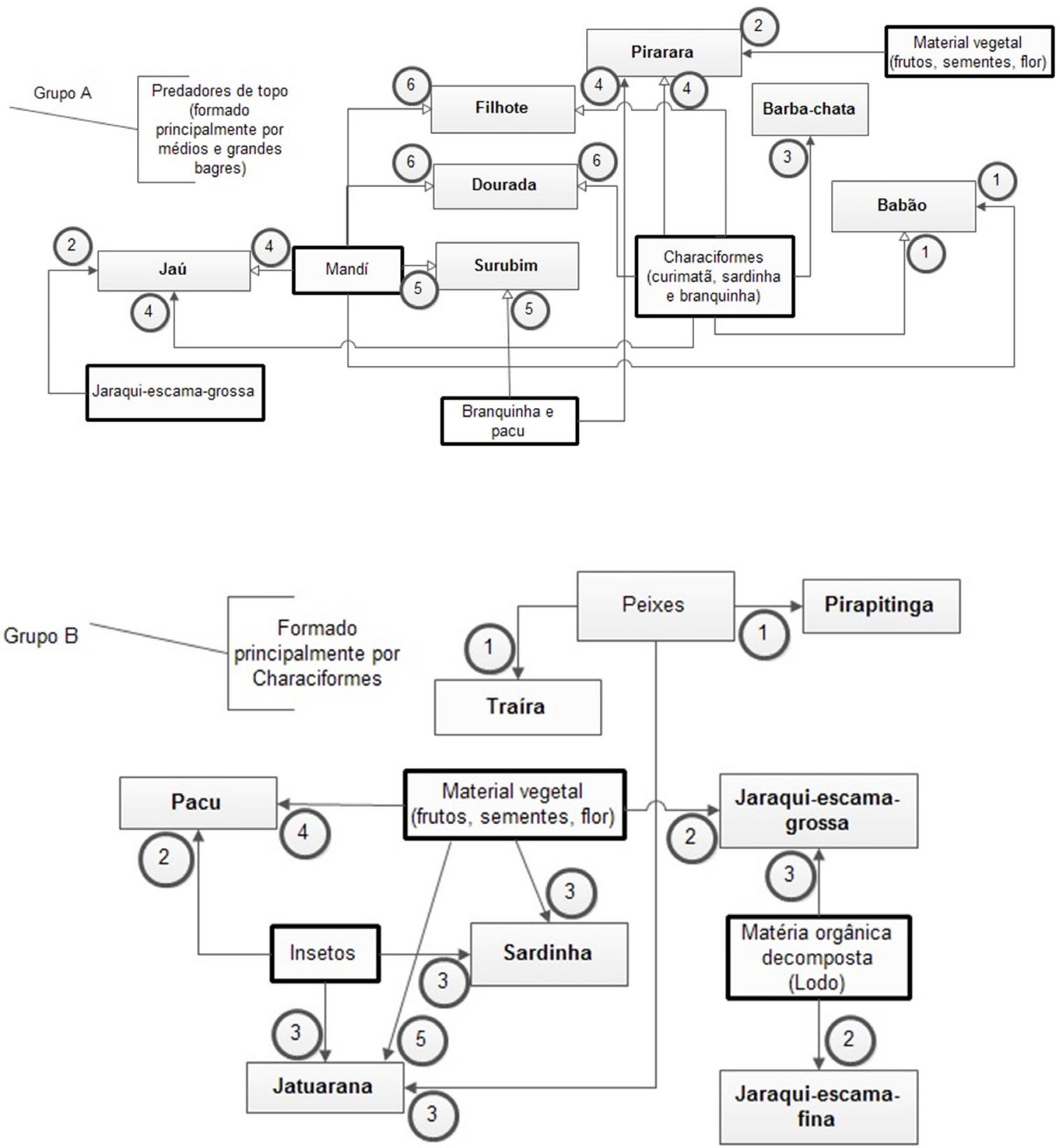

FIGURA 3 - Cadeia trófica baseada nas presas e predadores mais citados por pescadores na porção médio do rio Madeira. Legenda: Grupo A = Siluriformes; Grupo B = Characiformes. Os números correspondem ao número absoluto das comunidades que mencionaram cada interação trófica. 
O acúmulo de gordura abdominal foi verificado comparativamente com dados da pesca experimental para 22 categorias de pescado ( $81 \%$ do total de 27 categorias). O CET confirmou a informação experimental para 16 categorias (72\%). O filhote, o jaú e a pirapitinga são identificados como espécies que possuem um alto índice de gordura. Não houve consenso no CET dos pescadores sobre acúmulo de gordura na cavidade abdominal apenas para duas espécies.

TABELA 3 - Resultados obtidos para o período mencionado como melhor condição (gordura) para as categorias de pescado comercializadas em Rondônia e Humaitá (AM), de acordo com o conhecimento ecológico tradicional (CET) dos pescadores locais, comparados ao período gordo observado nas pescarias experimentais. Legenda: CET = Informação dos pescadores; EXP = Informação experimental; $\operatorname{Fr}(\%)$ = Frequência relativa do número de respostas.

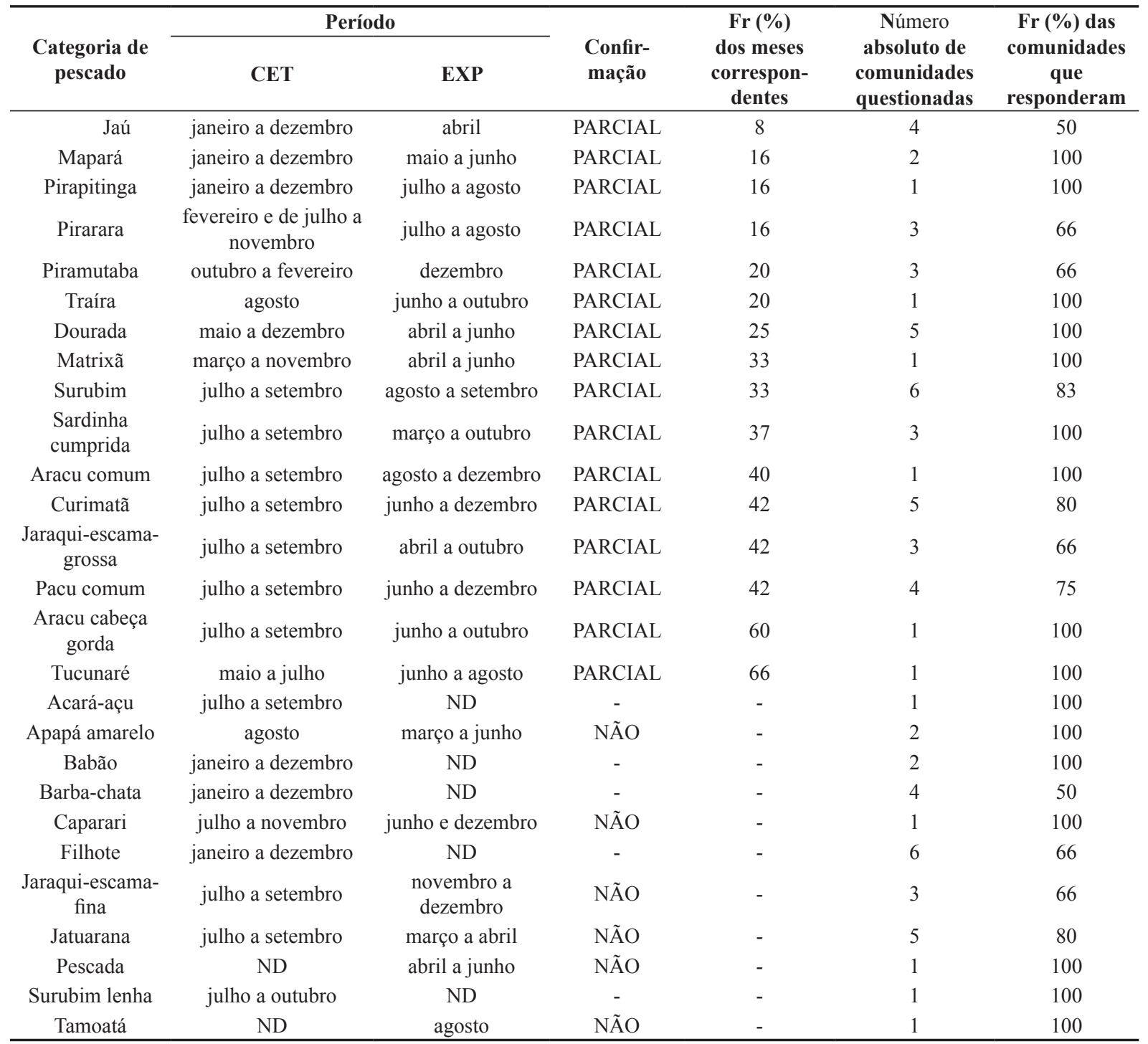


Poucos pescadores relataram conhecimento sobre o período reprodutivo dos peixes (Tabela 4). Do total de 20 categorias de pescado analisadas, nove foram capturadas na pesca experimental e puderam ser avaliadas. $\mathrm{O}$ CET confirmou a informação experimental para cinco categorias $(55 \%)$.

A literatura pesqueira indica que aquelas espécies para as quais os pescadores não revelaram conhecimento sobre o período reprodutivo de fato não se reproduzem nessa região da bacia do rio Madeira, o que justificaria a ausência de coleta de dados etnoictiológicos e na pesca experimental. Dentre elas encontramos a dourada e o filhote (Brachyplatystoma rouseauxii e B. filamentosum), que se reproduzem na parte à montante do rio Madeira, de acordo com Barthem e Goulding (2007).
Conforme informado pelos pescadores, a época mais favorável à reprodução da maioria das espécies é a enchente (novembro a janeiro), exceto para o pirarucu, cujo período de reprodução se estende até a cheia (novembro a abril) e para espécies como o jaú e o tucunaré, cujo período de reprodução ocorre durante a seca (agosto a outubro) (Tabela 4).

O tamanho da primeira maturação foi informado pelos pescadores para a maioria das espécies-alvo de suas pescarias (Tabela 5). O Conhecimento Ecológico Tradicional (CET) confirmou a informação experimental (EXP) ou da literatura para 14 categorias de pescado $(73 \%)$ dentre as 19 disponíveis. Possivelmente as diferenças observadas entre o CET e a EXP representam valores observados na pesca experimental menores dos

TABELA 4 - Resultados obtidos para o período reprodutivo das categorias de pescado comercializadas na porção média do rio Madeira de acordo com o conhecimento ecológico tradicional (CET) dos pescadores locais, comparados ao período reprodutivo observado nas pescarias experimentais. Legenda: $\mathrm{CET}=$ Informação dos pescadores; $\mathrm{EXP}=$ Informação experimental; Fr $(\%)=$ Frequência relativa do número de respostas.

\begin{tabular}{|c|c|c|c|c|c|c|}
\hline \multirow{2}{*}{$\begin{array}{l}\text { Categoria do } \\
\text { Pescado }\end{array}$} & \multicolumn{2}{|c|}{ Período } & \multirow{2}{*}{$\begin{array}{l}\text { Confir- } \\
\text { mação }\end{array}$} & \multirow{2}{*}{$\begin{array}{l}\text { Fr }(\%) \text { dos } \\
\text { meses } \\
\text { corres- } \\
\text { pondentes }\end{array}$} & \multirow{2}{*}{$\begin{array}{c}\mathrm{N}^{0} \text { das } \\
\text { comunidades } \\
\text { questio- } \\
\text { nadas }\end{array}$} & \multirow{2}{*}{$\begin{array}{c}\text { Fr }(\%) \text { das } \\
\text { comunidades } \\
\text { que respon- } \\
\text { deram }\end{array}$} \\
\hline & FEK & EXP & & & & \\
\hline Sardinha comprida & novembro a dezembro & agosto a janeiro & PARCIAL & 33 & 3 & 100 \\
\hline Pacu comum & novembro a janeiro & outubro a fevereiro & PARCIAL & 60 & 3 & 100 \\
\hline Curimatã & novembro a janeiro & dezembro a janeiro & PARCIAL & 66 & 3 & 100 \\
\hline Jaraqui-escama-fina & novembro a dezembro & outubro a dezembro & PARCIAL & 66 & 2 & 100 \\
\hline Jatuarana & novembro a janeiro & dezembro a janeiro & PARCIAL & 66 & 4 & 100 \\
\hline Acará-açu & novembro & ND & - & - & 1 & 100 \\
\hline Aracu cabeça-gorda & ND & outubro a dezembro & - & - & 1 & 100 \\
\hline Aracu comum & janeiro & $\begin{array}{c}\text { novembro a } \\
\text { dezembro }\end{array}$ & NÃO & - & 1 & 100 \\
\hline Barba-chata & novembro a janeiro & ND & - & - & 2 & 50 \\
\hline Caparari & ND & ND & - & - & 1 & 100 \\
\hline Dourada & abril & ND & - & - & 4 & 25 \\
\hline Filhote & ND & ND & - & - & 3 & 100 \\
\hline $\begin{array}{l}\text { Jaraqui-escama- } \\
\text { grossa }\end{array}$ & ND & outubro a dezembro & - & - & 2 & 100 \\
\hline Jaú & ND & ND & - & - & 1 & 100 \\
\hline Matrixã & dezembro & novembro & NÃO & - & 1 & 100 \\
\hline Piramutaba & ND & ND & - & - & 1 & 100 \\
\hline Pirarara & novembro a janeiro & ND & - & - & 2 & 100 \\
\hline Surubim & novembro & ND & - & - & 4 & 50 \\
\hline Surubim lenha & ND & ND & - & - & 1 & 100 \\
\hline Tamoatá & ND & ND & - & - & 1 & 100 \\
\hline
\end{tabular}


TABELA 5 - Conhecimento Ecológico Tradicional (CET) sobre tamanho de primeira reprodução (comprimento padrão em cm) de espécies de peixe alvo da pesca nas localidades compreendidas no trecho de estudo. Em negrito os valores confirmados. Legenda: (1) (Santos, 2006); (2) (Sánchez-Botero \& Araújo Lima, 2001); (3) (García Vásquez et al., 2009); (4) (Petrere Jr. et al., 2004); (5) (Vazzoler \& Caraciolo-Malta, 1983).

\begin{tabular}{|c|c|c|c|}
\hline CATEGORIAS & $\begin{array}{l}\text { INFORMAÇÃO CET } \\
(\mathrm{mm})\end{array}$ & $\begin{array}{l}\text { INFORMAÇÃO EXP } \\
(\mathrm{mm})\end{array}$ & INFORMAÇÃO CIENTÍFICA \\
\hline Acará-açu & 150 & 190 & 250 (1) 130,7 (2) \\
\hline Curimatã & $200-300$ & 150 & $260(1) ; 220(2)$ \\
\hline Dourada & 1110 & 780 & $1000(1) ; 780-1000(3)$ \\
\hline Filhote/Piraíba & $600-900$ & & $\mathbf{8 8 0}(4)$ \\
\hline Jaraqui-escama-fina & $200-250$ & 170 & $250(5) ; 160,5(2)$ \\
\hline Jaraqui-escama-grossa & 200 & 170 & $250(5) ; 160,5(2)$ \\
\hline Jatuarana & $250-300$ & 340 & $320(1)$ \\
\hline Jaú & 600 & & $1200(1)$ \\
\hline Pacu & $150-200$ & 120 & $190(1) ; 130,7(2)$ \\
\hline Piau & 150 & & \\
\hline Piramutaba & $300-450$ & & $\mathbf{5 0 0}(1)$ \\
\hline Piranha caju & 120 & & $\begin{array}{c}130 \text { (machos) e } 150 \text { (fềmeas) (1); } \\
\text { 130,7 (2) }\end{array}$ \\
\hline Pirapitinga & $300-450$ & 130 & \\
\hline Pirarucu & 1500 & & 1600 a $1850(1)$ \\
\hline Sardinha & 200 & 130 & $130,7(2)$ \\
\hline Surubim & $300-450$ & 570 & $450(1)$ \\
\hline Tamoatá & 120 & 140 & $90(1) ; 110(2)$ \\
\hline Traira & 250 & 200 & $150(1) ; 160(2)$ \\
\hline Tucunaré & 200 & 200 & $\begin{array}{c}23 \text { (machos) } 27 \mathrm{~cm} \text { (fê- } \\
\text { meas) (1) }\end{array}$ \\
\hline
\end{tabular}

que os observados pelo CET e estão relacionados à metodologia de coleta, visto que na EXP são utilizadas malhadeiras com distância entre nós (entre 4 e $8 \mathrm{~cm}$ ) que não são permitidas na pescaria comercial, dificultando a captura de indivíduos de pequeno porte e a observação desta informação para estes indivíduos pelos pescadores.

\subsection{Conflitos e cenários para a atividade pesqueira}

As informações obtidas a partir da análise e construção de mapas mentais levaram os pescadores a refletirem sobre suas ações e atitudes, analisar o seu espaço como lugar de vivência e a construção de cenários e espacialização de informações importantes no contexto da pesca no trecho estudado. É por intermédio dos processos perceptivos, a partir dos interesses e necessidades, que estruturamos e organizamos as interfaces entre realidade e mundo, selecionando-as, armazenando-as e conferindo-lhes significados (Kozel, 2001). O aporte da percepção fenomenológica proporcionou subsídios para a compreensão da realidade vivida pelos pescadores.

A interação, além de abrir espaços de negociação entre os atores, permite o surgimento de políticas com maiores chances de sustentabilidade quando se considera o conhecimento tradicional, complementado pelo 
conhecimento científico (Berkers et al., 2006). Um dos efeitos positivos dessas negociações é a diminuição dos conflitos da atividade pesqueira entre os diversos atores e o governo (Doria et al., 2008).

O principal motivo de conflito citado pelos pescadores foi disputa por áreas de pesca, que envolve diferentes atores e se reflete nas condições específicas de cada uma das localidades (Tabela 6). O conflito citado pelos pescadores de Humaitá pela "falta de área para pesca" está principalmente relacionado ao fato de que na região existe um grande número de Unidades de Conservação, onde a pesca é proibida. A "posse" de espaços de pesca (comunidades, moradores isolados e fazendeiros) ou, ainda, a institucionalização de áreas como Unidades de Conservação (UCs) e Terras Indígenas (reservas) em Rondônia, diminuiu as áreas historicamente exploradas pela pesca (Doria et al., 2012c). Apesar de haver regulamentação que proíbe a pesca nas UCs e reservas, os pescadores com frequência invadem essas áreas, acirrando a disputa pela apropriação desses espaços e do pescado neles contido.

Outro motivo também citado pelos pescadores das demais localidades estudadas foi que o número de pescadores aumentou e as áreas livres para pescar diminuíram; assim, a aglomeração dos pescadores em pesqueiros compartilhados vem aumentando a ocorrência de conflitos. Para acomodar os conflitos entre pescadores, eles estabelecem um conjunto de regras de ordenamento comunitário.

TABELA 6 - Motivos de conflito citados pelos pescadores, atores envolvidos e número de comunidades que apresentaram o conflito na percepção dos pescadores da porção média do Rio Madeira.

\begin{tabular}{|c|c|c|}
\hline Motivo & Atores envolvidos & $\begin{array}{c}\mathbf{N}^{\circ} \text { de co- } \\
\text { munidades }\end{array}$ \\
\hline \multirow{5}{*}{$\begin{array}{l}\text { Disputa por áreas } \\
\text { de pesca }\end{array}$} & Pescadores x Fazendeiros & 1 \\
\hline & $\begin{array}{l}\text { Pescadores x UHE Santo } \\
\text { Antônio }\end{array}$ & 1 \\
\hline & Pescadores x Ribeirinhos & 3 \\
\hline & $\begin{array}{l}\text { Pescadores x Pescadores } \\
\text { amadores }\end{array}$ & 1 \\
\hline & Pescadores x Pescadores & 1 \\
\hline $\begin{array}{l}\text { Agentes dos ór- } \\
\text { gãos ambientais }\end{array}$ & Fiscais & 5 \\
\hline
\end{tabular}

Em menor proporção, foi citado o conflito entre pescadores comerciais. Todavia, durante as reuniões para construção dos mapas mentais, quando se posicionavam como grupo, eles relataram a ocorrência de conflitos entre pescadores em todas as localidades, relacionados principalmente com a disputa de área de pesca (ver exemplo no mapa mental, Apêndice 1).

Com a implantação dos empreendimentos, a expectativa dos pescadores é que ocorra a intensificação desses conflitos, principalmente devido às mudanças no nível do rio, pelo posicionamento da barragem e por possíveis migrações de pescadores de áreas que serão hipoteticamente prejudicadas pela implementação das Hidroelétricas de Jirau e Santo Antônio em direção às localidades onde a pesca continuaria "boa" (Apêndice 1). Pode-se identificar esse sentimento nas falas a seguir:

\begin{abstract}
Maior parte dos pescadores pescam no rio Jacy, de onde vem boa parte da produção e o espaço de pesca atual não supre a quantidade de pescadores que existe no Jacy. Os pescadores estão espremidos entre as duas hidroelétricas e estão ficando sem opção. Com a implantação do empreendimento os peixes irão diminuir e de dois anos para cá já houve uma diminuição na quantidade de peixe. $O$ motivo da diminuição foi devido à grande mortandade de peixe no resgate e devido à quantidade de bombas e à claridade ficam poucos peixes (Pescadores de Jacy-Paraná).
\end{abstract}

Os cenários futuros simulados pelos pescadores revelaram preocupação com o desaparecimento de espécies que são alvo da pesca atual devido ao aumento no nível do rio ocorrido a partir da implantação da barragem. Essa preocupação com os impactos negativos que seriam causados pelo empreendimento é identificada na seguinte fala:

\begin{abstract}
A água parou de correr, represou aqui na frente, porque a usina já tampou parte do canal. A bomba atrapalha na hora da passagem dos peixes. Mandi, piau, pacu, sardinha, branquinha, cascudinho, curimba, não passaram. Antes subiam o mandi, pacu, piau, cascudinho, branquinha, sardinha, curimba, agora não. Esses peixes eram usados como isca e teve que usar o surubim. Perdeu a velocidade em Santo Antônio, por isso não subiu até o Teotônio tiraram os canais e ficou só um e não subiu...
\end{abstract}


Lá embaixo São Carlos, Calama e outros têm peixe e aqui não (Pescador da Cachoeira do Teotônio).

Os pescadores ainda demonstraram muitas dúvidas sobre os impactos que poderiam ser causados na pesca pelos empreendimentos. No imaginário dos pescadores de muitas localidades, haverá a inundação de grandes áreas nas localidades do reservatório (ex. Jacy-Paraná e Cachoeira do Teotônio) e aumento no nível da água, mesmo em locais à jusante (ex. Humaitá). Essa falta de informação causa insegurança, além de não deixar claros os reais impactos e mudanças ambientais vislumbrados por eles e que poderão de fato ocorrer, interferindo diretamente na dinâmica da atividade pesqueira exercida na região. A esse respeito os pescadores da Humaitá expõem que:

Esse ano o nivel do rio está completamente incomum, está havendo muitos repiquetes. É a primeira vez que está acontecendo isso. Por causa da obra porque está mexendo na natureza. Hoje anoitece enchendo e muito e amanhece secando. Os peixes que mais sentiram foram os peixes de ova. Porque não sai do igarapé quando há essa oscilação no rio. O rio secando o peixe não sai (Pescador de Humaitá).

A ocorrência de repiquetes e variações irregulares e até diárias é observada também em anos anteriores (observação pessoal do primeiro autor). Estas variações, sejam de origem natural ou antrópica, ocasionam mudanças que alteram o comportamento das assembleias de peixes, em especial porque interferem na regularidade da descontinuidade serial local (Ward \& Standford, 1995) e antecipam a migração lateral, que representa uma interação ecológica para várias espécies de peixes (Okada et al., 1996; Agostinho et al., 2001; Agostinho \& Gomes, 2005).

No rio Paraná, fato semelhante foi relatado pelos pescadores após o fechamento da AHE de Porto Primavera. O problema associado era que os "repontos" (denominação local para repiquete) irregulares abriam passagem para os peixes até as lagoas marginais que são locais de reprodução, mas a curta duração deste pulso ocasional fazia diminuir rapidamente o volume de água em muitas das lagoas marginais alcançadas pelos peixes, retendo-os em áreas proibidas para a pesca (Carvalho, 2002).

De fato, o enchimento contínuo do rio, nos meses de outubro a dezembro, para algumas regiões da Amazônia, é considerado um estímulo para a subida de alguns cardumes, que saem dos lagos de várzea e matas de igapó para o rio principal, iniciando a migração (Goulding, 1979). Da mesma forma, baixos níveis de água por períodos relativamente longos e continuadamente podem causar a queda do recrutamento para o próximo ano, com consequências na pesca dos anos subsequentes (Welcomme, 1979).

O registro etnoecológico deste evento no rio Madeira mostrou que os pescadores detêm um refinado conhecimento da ecologia do ambiente onde atuam, o que permite a detecção de variações nos padrões ou na dinâmica vivenciada por eles ao longo de anos. Estas informações podem indicar a necessidade de uma melhor avaliação de determinados fenômenos e, em se constatando a ocorrência destas variações, a necessidade de medidas que podem ser adotadas para minimizar seus efeitos sobre o recurso pesqueiro.

\section{Conclusão}

Este estudo confirma o refinado conhecimento que o pescador possui sobre a biologia das espécies exploradas e sugere que o CET pode ser utilizado para:

1 - obtenção de dados biológicos complementares aos dados científicos em estudos de licenciamento ambiental de grandes empreendimentos para:

i. fornecer respostas e informações que podem atender aos requisitos de representatividade de área amostral sob a influência do projeto de construção e compatibilidade com o ciclo biológico do grupo alvo da amostragem, considerando que os pescadores, quando presentes na região, atuam em toda a área de influência;

ii. auxiliar na avaliação dos impactos em uma escala temporal, já que os pescadores detêm as informações pretéritas e podem acompa- 
nhar diariamente as variações ambientais e auxiliar na previsão de impactos ou alterações futuras;

iii. para estudos de licenciamento ambiental na Amazônia, haja vista as dificuldades na obtenção de dados devido ao custo elevado para a realização da pesquisa in loco resultante das dificuldades logísticas inerentes à região, e a ausência de dados pretéritos pode ser diminuída pelo uso do CET para o preenchimento de lacunas de conhecimento e a determinação do desenho experimental dos levantamentos de dados, otimizando o tempo e os investimentos da pesquisa científica;
2 - construção de cenários referentes à atividade pesqueira, bases para o manejo adaptativo na fase de monitoramento dos empreendimentos, bem como para o planejamento de políticas da gestão pesqueira na região, além de contribuir com o sucesso e sustentabilidade destas políticas por meio da efetiva participação dos atores sociais diretamente envolvidos;

3 - ademais, o CET propicia a aferição e o monitoramento contínuo do ambiente e das espécies biológicas frente aos impactos proporcionados pelas modificações resultantes da implantação dos empreendimentos e, de forma complementar, na avaliação dos indicadores que estão sendo empregados no monitoramento, na quantificação e na mitigação dos possíveis impactos.

\section{Referências}

Agostinho, A. A.; Gomes, L. C. O manejo da pesca em reservatórios da bacia do alto rio Paraná: avaliação e perspectivas. In: Nogueira, C.; Henry, R. Ecologia de reservatórios: impactos potenciais, ações de manejo e sistemas em cascata. São Carlos: Rima, 2005. p. 23-55.

; Ferretti, C. M. L.; Gomes, L. C.; Hahn N. S.; Suzuki, H. I.; Fugi, R.; Abujanra, F. Ictiofauna de dois reservatórios do rio Iguaçu em diferentes fases de colonização: Segredo e Foz do Areia. Cap. 15. p. 275-292. In: Agostinho, A. A.; Gomes L. C. (Ed.). Reservatório de Segredo: bases ecológicas para o manejo. Maringá: EDUEM, 1997.

; Suzuki, H. I.; Julio Jr., H. F. Riscos da implantação de cultivos de espécies exóticas em tanques redes em reservatórios do Rio Iguaçu. Cadernos da Biodiversidade, 2(2), 9, 1999.

; Zalewski, M. The importance of floodplains for the dynamics of fish communities of the upper river Paraná. Ecohydrol. Hydrobiol., 1(1-2), 209-217, 2001.

Ankei, Y. Folk-knowledge of the fish among the Songola and the Bwari: comparative ethnoichthyology of the Zaire River and Lake Tanganyica fishermen. Africa Kenkyu, 21, 1-56, 1982.

Azevedo, C. R. de; Apel, M. Cogestão: um processo em construção na várzea amazônica. Estado do Pará - Estudo Estratégico-Analítico. Manaus, Brasil: ProVárzea/Ibama, 2004.
Barboza, R. S. L.; Pezzuti, J. C. B. Etnoictiologia dos pescadores artesanais da Resex Marinha Caeté - Taperaçu, Pará: aspectos relacionados com etologia, usos de hábitat e migração de peixes da família Sciaenidae. Sitientibus série Ciências Biológicas, 11(2), 133-141, 2011.

Barthem, R. B.; Goulding, M. Um ecossistema inesperado: a Amazônia revelada pela pesca. Lima, Peru: Amazon Conservation Association (ACA) - Sociedade Civil Mamirauá, 2007.

Batista V. S.; Isaac V. J.; Viana, J. P. Exploração e manejo dos recursos pesqueiros da Amazônia. In: Ruffino, M. L. (Coord.). A pesca e os recursos pesqueiros na Amazônia Brasileira. Manaus, Brasil: IBAMA/ProVárzea, 2004.

Batistella, A. M.; Castro, C. P.; Vale, J. D. Conhecimento dos moradores da comunidade de Boas Novas, no lago Januacá Amazonas, sobre os hábitos alimentares dos peixes da região. Acta Amazonica, 35(1), 51-54, 2005.

Begossi, A. Fishermen's local ecological knowledge on Southeastern Brazilian coastal fishes: contributions to research, conservation, and management. Neotropical Ichthyology, 10(1), 133-147, 2012.

; Garavello, J. C. Notes on the ethnoichthyology from Tocantins River. Manaus-AM. Acta Amazonica, 20, 341-351, 1990. 
; Figueiredo, J. L. Ethnoichthyology of southern coastal fishermen: cases from Buzios Island and Sepetiba Bay (Brazil). Bull. Mar. Sci., Miami, 56(2), 682-689, 1995.

Berkers, F.; Mahon, R.; McConney, P.; Pollnac, R.; Pomery, R. (autores da versão original em inglês). Kaliskoski, D. C. (Org. edição em português). Gestão de pesca de pequena escala: diretrizes e métodos alternativos. Rio Grande, Brasil: Ed. UFRG, 2006.

Bonner, T. H.; Wild, G. R. Changes in the Canadian River Fish Assemblage Associated with Reservoir Construction. Journal of Freshwater Ecology, 15(2), 2000.

Britski, H. A. A fauna de peixes brasileiros de água doce e o represamento de rios. In: Anais do COMASE: Seminário sobre fauna aquática e o setor elétrico. Rio de Janeiro, v. 1, 1994. p. 23-30.

Carvalho, A. R. Conhecimento ecológico tradicional no fragmento da planície de inundação do alto rio Paraná: percepção ecológica dos pescadores. Acta Scientiarum, 24(2), 573-580, 2002.

Costa-Neto, E. M.; Dias, C. V; Melo, M. N. O conhecimento ictiológico tradicional dos pescadores da cidade de Barra, região do médio São Francisco, Estado da Bahia, Brasil. Acta Scientiarum, Maringá, 24(2), 561-572, 2002.

Diegues, A. C. Brazil: Environmental Impact Assessments. The view from the other side. Samudra-Rep., 16, 3-9, 1996.

; Arruda, R. S. V.; Silva, V. C. F.; Figols, F. A. B.; Andrade, D. Os saberes tradicionais e a biodiversidade no Brasil. Ministério do Meio Ambiente, dos Recursos Hídricos e da Amazônia Legal. Núcleo de Pesquisas sobre Populações Humanas e Áreas Úmidas Brasileiras - NUPAUB. São Paulo: Universidade de São Paulo - USP, 2000.

Doria, C. R. C.; Brasil-de-Souza, S. T. A pesca nas bacias dos rios Guaporé e Baixo Mamoré, Amazônia brasileira. In: Van Damme, Paul A.; Maldonado, Mabel; Pouilly, Marc; Doria, Carolina R. C. (Org.). Aguas del Iténez o Guaporé. Recursos hidrológicos de un patrimonio binacional. Bolivia-Brasil. 1 . ed. Cochabamba: INEA, 2012. p. 249-260.

; Araujo, T. R.; Brasil-de-Souza, S. T.; Torrente-Vilara, G. Contribuição da etnoictiologia à análise da legislação pesqueira referente ao defeso de espécies de peixes de interesse comercial no oeste da Amazônia Brasileira, rio Guaporé, Rondônia, Brasil. Biotemas (UFSC), 21, 119-132, 2008.

Ruffino, M. L.; Hijazi, N. C. A pesca comercial na bacia do rio Madeira no Estado de Rondônia, Amazônia. Acta Amazonica (Impresso), 42, 29-40, 2012a.
; De Queiroz, L. J.; Torrente-Vilara, G.; Leite, R. G.; Ropke, C. P.; Cella-Ribeiro, A.; Ohara, W.; Lima, M. A. L.; Zuanon, J. S. Monitoramento da ictiofauna do rio Madeira. Ação Ambiental (UFV), 1, 28-34, $2012 \mathrm{~b}$.

; Ropke, C. P.; Cella-Ribeiro, A.; Torrente-Vilara, G. Conhecimento e gestão do recursos pesqueiros na Bacia do rio Guaporé no território brasileiro. In: Van Damme, Paul A.; Maldonado, Mabel; Pouilly, Marc; Doria, Carolina R. C. (Org.). Aguas del Iténez o Guaporé. Recursos hidrológicos de un patrimonio binacional. Bolivia-Brasil. 1. ed. Cochabamba: INIA, 2012c. p. 243-248.

Drew, J. A. Use of traditional ecological knowledge in marine conservation. Conservation Biology, 19(4), 1286-1293, 2005.

Ferraz, G. Twelve Guidelines for Biological Sampling in Environmental Licensing Studies. Natureza \& Conservação, 10(1), 20-26, 2012.

Galvão de Lima, L.; Batista, V. S. Estudos etnoictiológicos sobre o pirarucu (Arapaima gigas) na Amazônia Central. Acta Amazonica, 42(3), 337-344, 2012.

Garcia Vasquez, A.; Alonso, J. C.; Carvajal, F.; Moreau, F.; Nunez, J.; Renno, J. R.; Tello, S.; Montreuil V.; Duponchelle, F. Life-history characteristics of the large Amazonian migratory catfish Brachyplatystoma rousseauxii in the Iquitos region, Peru. Journal of Fish Biology, 75, 2527-2551, 2009.

Gerhardinger, L. C.; Bertoncini A. A.; Hostim-Silva, M. Local ecological knowledge and Goliath grouper spawning aggregations in the South Atlantic Ocean: Goliath grouper spawning aggregations in Brazil. SPC Traditional Marine Resource Management and Knowledge Information Bulletin, 20, 33-34, 2006.

Giusti, M. del C. H. Conflictos ambientales en la gestión del Santuario Histórico de Machupicchu: El Caso de la Instalación y Manejo de la Central Hidroeléctrica Machupicchu. Cusco. Tese (Master en Ciencias Sociales con Mención en Gestión Ambiental y Desarrollo) - Escuela Andina de Post-Grado Maestría en Gestión Ambiental y Desarrollo.), 2005.

Goulding, M. R. Ecologia da pesca do rio Madeira. Manaus: CNPq/INPA, 1979. 172 p.

; Barthem, R.; Ferreira, E. The Smithsonian Atlas of the Amazon. Smithsonian Books, Washington, USA, 42(3), 253, 2003.

Holling, C. S. Resilience and Stability of Ecological Systems. Annual Review Ecology and Systematics, 4, 1-23, 1973.

Johannes, R. E. Fishing and traditional knowledge: a collection of essays. Gland: IUCN, The World Conservation Union, 1989. 
The case for data-less marine resource management: examples from tropical nearshore finfisheries. Trends in Ecology and Evolution, 13(6), 243-246, 1998.

Kozel, S. T. Das imagens às linguagens do geográfico: Curitiba, a “Capital Ecológica”. 310 p. São Paulo, Tese (Doutorado) - Universidade de São Paulo, 2001.

Kubecka, J. Succession of fish communities in reservoirs of Central and Eastern Europe. c.11, p. 153-168. In: Straskraba, M.; Tundisi, J. G.; Duncan, A. (Ed.). Comparative reservoir limnology and water quality management. Dordrecht-Holland: Kluwer Academic, 1993.

Lowe-McConnell, R. H. The status on Southern America freshwater food fish. In: Zaret, T. M. (Ed.). Evolutionary Ecology of Neotropical freshwater fishes. The Netherlands: Dr. W. Junk, 1984. p. 173.

Meffe, G. K.; Nielsen, L. A.; Knight, R. L.; Schenborn, D. A. Ecosystem Management - Adaptive Community-Based Conservation. Ed. Island Press, 2002. p. 333.

Morril, W. T. Ethnoichtyology of the Cha-Cha. Ethology, 4, 405-416, 1967.

Okada, E.K. et al. Catch and effort data and the management of the commercial fisheries of Itaipu reservoir in the upper Paraná river, Brazil. In: Cowx, I. G. (Ed.). Stock and Assessment in inland fisheries. Fishing New Books. Blackwell Science Ltda., 1996.

Petrere Jr., M.; Barthem, R. B.; Córdoba, E. A.; Gómez, B. C. Review of the large catfish fisheries in the upper Amazon and the stock depletion of piraíba (Brachyplatystoma filamentosum Lichtenstein). Reviews in Fish Biology and Fisheries, 14(4), 403-414, 2004.

Pettesse, M. L.; Petrere, Jr., M. As barragens e os peixes: O impacto das grandes hidrelétricas nas espécies dos rios represados. Ciência Hoje, São Paulo, 49(293), 30-35, 2012.

Richter, B. D.; Braun, D. P.; Mendelson, M. A.; Master L. L. Threats to imperiled freshwater fauna. Conservation Biology, 5(11), 1081-1093, 1997.

Rodríguez Ruiz, A. Fish species composition before and after construction of a reservoir on the Guadalete River (SW Spain). Stuttgart. Archiv für Hydrobiologi, 142(3), 353-369, 1998.
Ruddle, K. Systems of knowledge: dialogue, relationships and process. In: Begossi, A.; Hens, L. Environment, development and sustainability, Kluwer Academic Publishers, 12(3-4), 2000.

Sánchez-Botero, J. L.; Araújo-Lima, C. A. R. M. As macrófitas aquáticas como berçário para a ictiofauna da várzea do rio Amazonas. Acta Amazonica, 31(3), 437-447, 2001.

Santos, G. M. Pesca e ecologia dos peixes de Rondônia. Manaus, Amazonas. Tese (Doutorado) - Instituto Nacional de Pesquisas da Amazônia, 1991.

; Ferreira, E. J. G.; Zuanon, J. A. S. Peixes comerciais de Manaus. Manaus: IBAMA-AM/ProVárzea, 2006. p. 144.

Sardà, F.; Maynou, F. Assessing perceptions: do Catalan fishermen catch more shrimp on Fridays? Fisheries Research, 36, 149-157, 1998.

Silvano, R. A. M.; Begossi, A. Ethnoichthyology and fish conservation in the Piracicaba river (Brazil). Journal of Ethnobiology, 22(2), 285-306, 2002.

;Valbo-Jorgensen, J. Beyond fishermens tales: contributions of fishers local ecological knowledge to fish ecology and fisheries management. Environment, Development and Sustainability, 10, 657-675, 2008.

Torrente-Vilara, G. Heterogeneidade ambiental e diversidade ictiofaunistica do trecho de corredeiras do rio Madeira, Rondônia, Brasil. Manaus, Amazonas. Tese (Doutorado em Biologia de Água Doce) - Instituto Nacional de Pesquisas da Amazônia, 2009.

Vazzoler, A. E. A. M. Biologia da reprodução de peixes teleósteos: teoria e prática. Maringá, Brasil: EDUEM, 1996.

; Caraciolo-Malta, M. C. Local e época de desova e início da primeira maturação sexual das espécies do gênero Prochilodus da bacia Amazônica. In: Livro Resumo da 35. ${ }^{a}$ Reunião da SBPC, p. 530, 74 - E-1, 1983.

Ward, J. V.; Standford, J. A. The serial discontinuity concept: extending the model to floodplain rivers. Regul. Rivers Res. Manag., Chichester, 10, 159-168, 1995.

Welcomme, R. L. Fisheries ecology of floodplain rivers. London \& New York: Longman, 1979. 


\section{Apêndice 1}

(a)

\section{SÃO CARLOS \\ Cenário Atual}

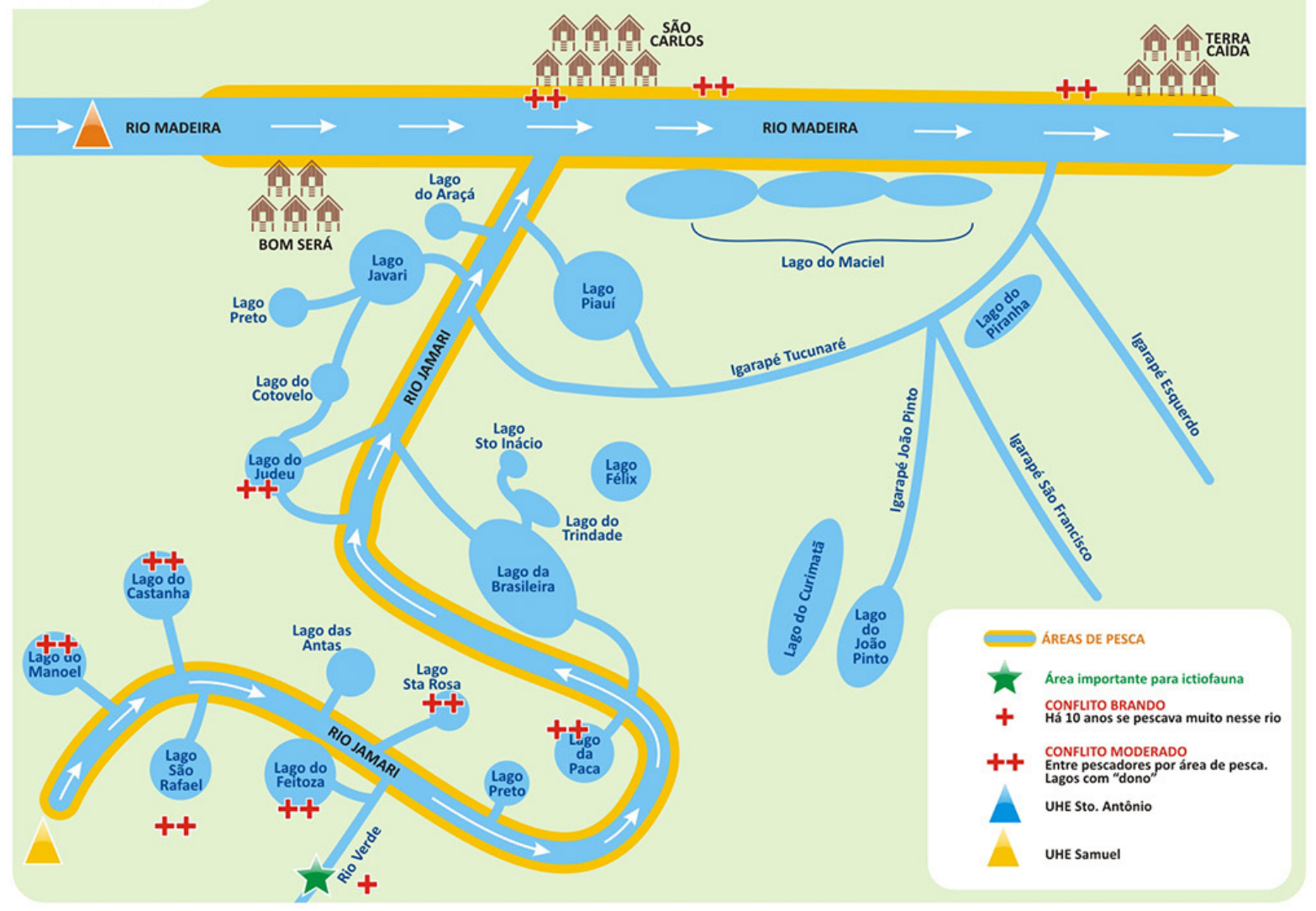


(b)

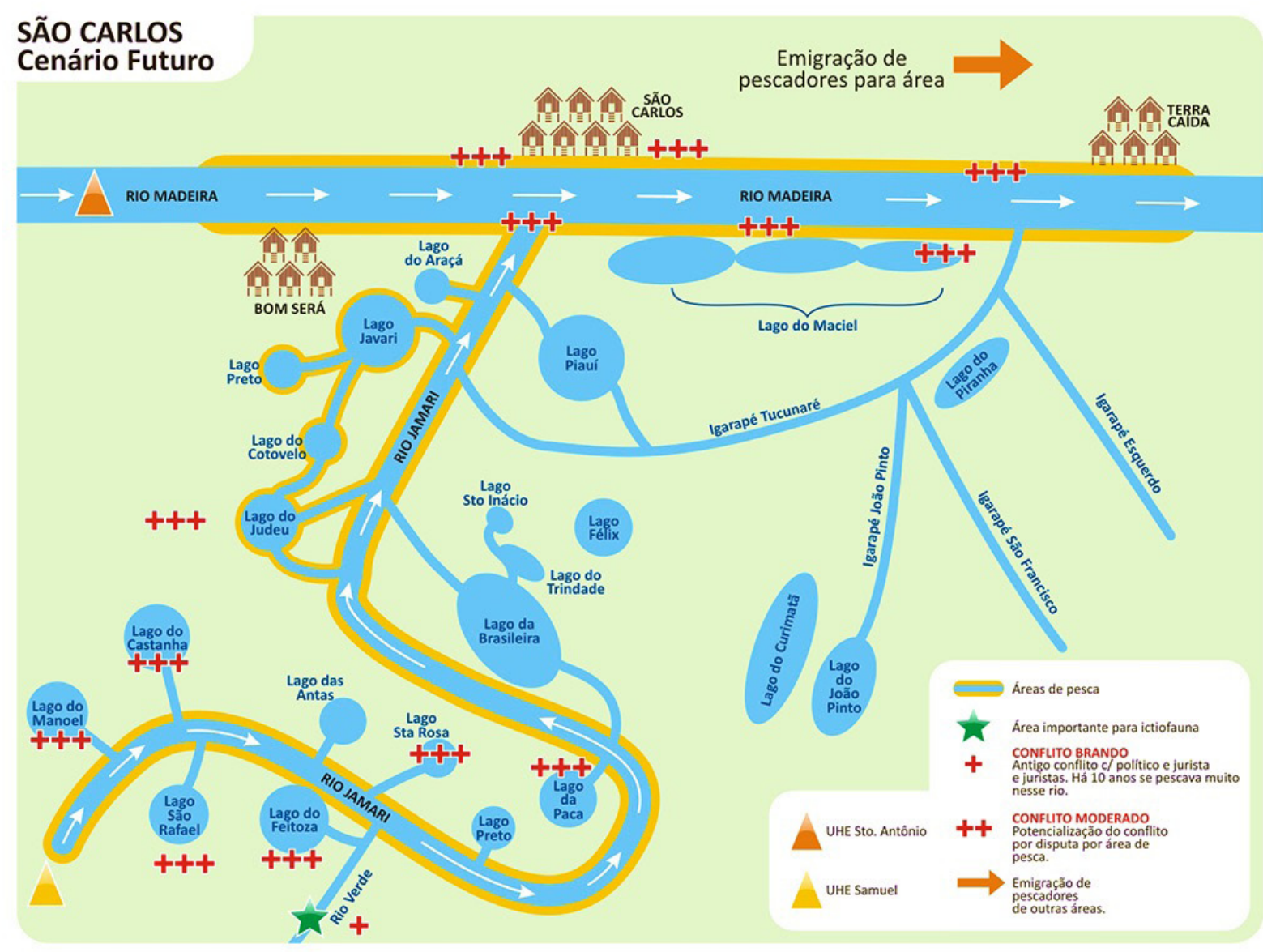

Mapa mental dos pescadores de São Carlos, localidade na área à jusante da UHE de Santo Antônio, com a representação do cenário atual (a) e hipótese de cenário futuro (b) a partir da instalação do Empreendimento. 